\title{
Construction Progress of Deep Underground Salt Cavern Gas Storage and Challenges of its Drilling and Completion Technology
}

\author{
Yi Zhang *, Jun Niu, Guoxing Chai Wenqi Ke and Hao Zeng \\ Petroleum Exploration and Production Research Institute of SINOPEC, Beijing, China
}

\begin{abstract}
With the rapid development of the national economy and the increasing demand for energy, and the acceleration of natural gas storage strategies, underground gas storage has become more and more important in China's oil and gas consumption and energy safety. Underground salt cavern gas storage has many advantages and is very suitable for gas storage and peak shaving。 However, most of the underground salt rocks in China are layered salt beds, and some of the salt beds are deeply buried. This article introduces the development history of deep underground salt cavern gas storage and the technical challenges faced in the process of drilling and completion of salt cavern construction.
\end{abstract}

\section{Introduction}

Underground gas storage is a key link in the natural gas industry chain and an important part of the pipeline transportation system. It not only adjusts the balance of supply and demand in the daily natural gas supply, but it also plays an irreplaceable role in an emergency situation in which an accident occurs. Underground gas storage has played a pivotal role in the natural gas storage system of various countries and has formed a relatively complete operating mechanism. Salt cavern gas storage uses dissolved salt mining to store natural gas in underground caves formed by mining salt rock in underground salt layers or salt domes as shown in Figure 1.

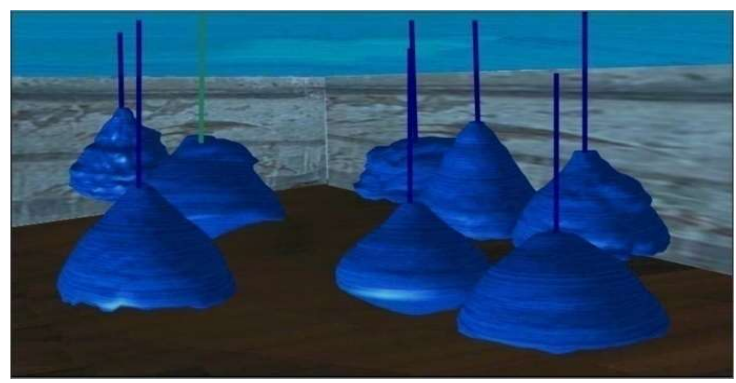

Figure 1. Schematic of underground gas storage

It has many advantages, such as flexible gas injection and production, large single well throughput, no leakage of gas storage, and high working gas ratio which is very suitable for gas storage and peak shaving $[1,2]$. The underground salt rocks in China are mostly layered salt beds, and some of the salt beds are deeply buried (about 2,000 meters), which makes the construction of salt cavern gas storages face more technical challenges in the process of drilling and completion [3].

\section{Deep Salt Cavern Gas Storage}

In the world, the buried depth of the salt cavern gas (oil) storage constructed by the water solution method is generally within $500-1500 \mathrm{~m}$. For example, the buried depth of the Huntorf salt cavern in Germany is about $700 \mathrm{~m}$, and the buried depth of the Hackberry salt dome cavern in Louisiana, United States is about $800 \mathrm{~m}$. At present, the salt cavern gas storages in the world with a depth of more than $1500 \mathrm{~m}$ mainly include the Harlingen brine production salt mine in the northern Netherlands $(2900 \mathrm{~m})$, the French Vauvert brine production salt mine $(1900 \mathrm{~m})$, the Eminence salt cavern gas storage in Mississippi (1800m) in the United States, Hornsea Aldbrough salt cavern gas storage in Yorkshire, UK $(1800 \mathrm{~m})$, Alberta Strathacona salt cavern gas storage in Canada (1786m), and Hornsea Atwick (1730m) in Yorkshire, UK. The following is a survey of the situation of these salt cavern gas storages.

\subsection{Harlingen Brine Salt Mine}

The Harlingen brine salt mine is located in the middle area of the Zechstein Salt Basin in the Netherlands, which is part of the Permian Basin in southern Europe. The salt rocks in the salt basin are mainly salt domes and salt pillow structures, which present the characteristics of large thickness and high salt content. For example, the thickness of salt rocks is generally greater than $500 \mathrm{~m}$, and the salt content is about $95 \%$. The Harlingen region is adjacent to the northern sea of the Netherlands and belongs to the province of Friesland. There are three gas storages in this area with a vertical buried depth of over $2900 \mathrm{~m}$. The gas storage was officially completed and put

\footnotetext{
* Corresponding author: zhangyi5801@yeah.net
} 
into operation in 1995. The cave is located in the Zechstein-2 salt rock layer, and the thickness of the salt rock layer is about $500 \mathrm{~m}$. The depth of the casing shoe is $2400-2500 \mathrm{~m}$, and there is a potash layer with a thickness of about $40 \mathrm{~m}$ at a position $20-30 \mathrm{~m}$ away from the casing shoe. The potash layer is mainly composed of carnallite, magnesium sulfate and potassium salt. The dividing line between the gypsum interlayer and the salt rock formation in the Zechstein-2 salt rock formation is relatively obvious, and the thickness of the gypsum interlayer is generally several centimeters to several meters [4].

\subsection{Vauvert Brine Salt Mine}

Located on the southeastern coast of France, the salt mine was once the main brine production base in France. The salt mine was discovered in 1962. The buried depth of the salt rock is between $1900 \mathrm{~m}$ and $3000 \mathrm{~m}$. The salt content in the salt rock is about $50 \%$. The other insoluble matter content is mainly gypsum and mudstone. Since 1973, the salt rock mining operation has been carried out by the water solution method. The Vauvert Salt Mine has 39 wells for brine production, of which 33 are located in the Parrapon mine and 6 wells are located in the La Galine mine. The distance between the two mines is $2.5 \mathrm{~km}$. The volume of a single cavity can generally reach 350,000 square meters to 1.4 million square meters. In the past 40 years, a total of 30 million tons of salt rock have been produced [5].

\subsection{Eminence Salt Cavern Gas Storage}

The Eminence Salt Cavern Gas Storage is located in the southwestern Mississippi, United States. The gas storage is located in a salt dome-type salt rock formation with a buried depth of between $1725 \mathrm{~m}$ and $2000 \mathrm{~m}$. The salt content in the salt rock formation is about $95 \%$, and the original in-situ stress of the target layer for building the reservoir is about $39 \mathrm{MPa}$. The first salt cavern gas storage in the area was completed and put into operation in 1970, namely Cavern-1. Cavern-1 was completed in January 1970, and the cavity shape was measured using sonar cavity measurement technology. The cavity height is about $250 \mathrm{~m}$ and the maximum diameter is about $50 \mathrm{~m}$. After it was completed in June of the same year, gas injection and brine removal operations began, and gas injection and brine removal were completed in October of that year. From October to December 1970, the gas storage maintained an operating internal pressure of 6 $\mathrm{MPa}$, after which the pressure increased to $28 \mathrm{MPa}$. In 1971, the same pressure mode was used for one year, but in the actual operation process, it was found that the injectable gas volume was significantly reduced, and the engineers suspected that the salt cavern volume had contracted greatly. In April 1972, engineers used sonar cavity measurement technology to measure Cavern-1 and found that the cavity bottom was raised by $36 \mathrm{~m}$, and the volume was reduced by about $40 \%$ compared with the measurement result in January, $1970[6,7]$.

\subsection{Hornsea Aldbrough Salt Cavern Gas Storage, Yorkshire}

The Hornsea Aldbrough Salt Cavern Gas Storage in Yorkshire, UK, is located on its southeastern coast and provides peak shaving gas for the British National Natural Gas Pipeline. The salt cavern gas storage is composed of a natural gas processing center and 9 caverns, and the roof depth of the gas storage is $1780 \mathrm{~m}-1830 \mathrm{~m}$. The earliest time to put the gas storage cavity into operation was June, 2011, and the latest time to put it into operation was November, 2012. The target stratum for the construction of the gas storage is located in the Permian and is a component of the Zechstein Formation. The salt rock formation contains thin interlayers, which alternate with salt rock layers; the main components of the interlayers are dolomite, mudstone and gypsum. According to the results of geological exploration, it can be seen that the Fordon salt rock layer (the target layer for Aldbrough gas storage construction) is rapidly thinning to pinch in the north, and rapidly increasing in the east, with a thickness of more than $300 \mathrm{~m}$. In the Aldbrough gas storage area, the thickness of the salt rock formation is about $280 \mathrm{~m}$, the top burial depth is $1660 \mathrm{~m}$, and the bottom burial depth is about 1940m [8]

\subsection{Strathacona Gas Storage, Alberta}

In Alberta, Canada, there are approximately 100 salt caverns used to store natural gas and industrial waste. They are concentrated in Fort Saskatchewan and Strathcona in Edmonton, Alberta ( Strathacona). Strathcona is located in the northeast area of Fort Saskatchewan. The Strathacona salt cavern gas storage is built in the Lotsberg formation, which has a buried depth of about $1900 \mathrm{~m}$ and a thickness of about $220 \mathrm{~m}$. The salt rock presents coarse-grained crystals with good transparency and the salt content can reach $99 \%$. The six salt cavern gas storages are operated by Northwest Utilities Company. It is built in a section of salt rock strata with a thickness of about $78 \mathrm{~m}$, and the roof of the cavity is about $1786 \mathrm{~m}$ deep.

\subsection{Hornsea Atwick Gas Storage, Yorkshire}

Hornsea Atwick gas storage is located in Yorkshire, England, adjacent to Aldrough gas storage. The total working gas volume of the gas storage is about $325 \times 10^{6}$ cubic meters, and the maximum daily gas production volume is $18 \times 10^{6}$ cubic meters. The cavity-building wellbore of Atwick No. 1 gas storage was completed in 1972, the first ultra-deep salt cavern gas storage built by the British Gas Company in Yorkshire. The gas storage is located in the Z2 salt layer. The top of the salt rock has a buried depth of $1770 \mathrm{~m}$ and a stratum dip of about 2 degrees. It is mainly composed of salt rock, gypsum, polyhalite, potassium carbonate, potash and a small amount of magnesia sulfate. During the construction of the Atwick gas storage, a well encountered a carnallite formation and was close to the fault. The well was eventually abandoned to build a gas storage. Therefore, S- 
type well trajectories are used in the drilling process in this area later to avoid the adverse effects of this layer. Well 1 is an exploratory well. During the drilling process, the $\mathrm{Z} 2$ salt formation was cored. Through analysis of the core, it is found that the $20 \mathrm{~m}$ thick formation in the upper part of Z2 salt rock contains $22 \%$ magnesia sulfate and a small amount of gypsum, and no potash is found. The salt cave in this area is designed as a cylinder with a dome, with a total height of $110 \mathrm{~m}$, a diameter of $95 \mathrm{~m}$, and a height of $10 \mathrm{~m}$ of insoluble matter. In order to avoid the adverse effects of carnallite and magnesite rock formations on the cavity creation and airtightness of the gas storage, the casing shoe is designed to be buried at a depth of $20 \mathrm{~m}$ (distance from the top of the salt rock). The thickness of the salt rock protection layer on the top of the salt cave is $20 \mathrm{~m}$, and the distance between the top of the salt cave and the upper layer of carnallite and magnesite is $40 \mathrm{~m}$ (this part is salt rock) [9]

\section{Drilling and Completion Process Challenges}

According to the statistics of the International Natural Gas Union (IGU), there are currently 737 underground gas storages in the world. The total working gas volume of underground gas storages is $4110 \times 10^{8} \mathrm{~m}^{3}$, and the maximum daily gas recovery (PWR) is about $67.7 \times 10^{8} \mathrm{~m}^{3} / \mathrm{d}$. Natural gas consumption annual growth rate has stimulated the global development of underground gas storage. Gas storage construction companies attach importance to basic research such as rock mechanics, string mechanics, and the management of well construction quality.

Gas storage injection and production wells are designed for life according to the principle of no workover for at least 30 years. At present, the Loenhout gas storage in Belgium has achieved this goal [10], and the TIGF gas storage in France has been in operation for more than 50 years. At present, only one well has abnormal casing pressure (except for the plugging well). The Norg gas storage in the Netherlands there was no abnormal casing pressure in the 6 production wells in the salt cavern for 14 years [11].

In order to meet the functions of seasonal peak shaving and emergency gas supply, gas storage injection and production wells need to meet the requirements of large flow injection and production, long life, and high safety. Larger-sized well structures should be adopted as far as possible. The material selection of the production casing and completion string of the gas storage is mainly determined by the quality of the gas injection and production. If there is a corrosion factor, the corresponding anti-corrosion material should be used, and the material selection is relatively conservative. For example, the gas production pipelines of Loenhout gas storage in Europe, Belgium, Yela gas storage and Norg gas storage in the Netherlands are all in diameter of $177.8 \mathrm{~mm}$ [12].

Under the condition of alternating stress, the cement ring of the wellbore of the gas storage is prone to micro-cracks and micro-annular space, resulting in the risk of gas channeling and casing pressure. In order to improve the cementing quality, the following measures are mainly suggested:

a) In the design of gas storage injection and production wells, the running depth of singlelayer casing should be controlled;

b) Pay attention to the cementing quality of each layer of casing and return the cement to the surface;

c) Using ductile expansive cement to reduce the influence of alternating stress on the cement ring;

d) Using self-healing cement technology to fill the micro cracks generated in the later stage;

e) Cementing quality inspection requirements are high, and ultrasonic imaging logging methods (such as IBC) are suggested.

\section{Conclusion}

Through decades of gas storage research and construction, people have greatly improved their understanding of the quality and requirements of gas storage construction, such as large-sized wellbore, reservoir drilling, horizontal wells, casing threaded gas seal testing, Advanced technologies and concepts such as elastic cement slurry and IBC logging have gradually been accepted by all parties in the construction of gas storage, which has played a very good role in promoting the construction of gas storage. Cementing should be the core of the drilling and completion of gas storage, and great attention should be paid to the wellbore integrity management of injection and production wells and old wells of gas storage. In particular, the quality of cementing of production liners and caps must be guaranteed.

\section{References}

1. P. Bérest, B. Brouard, J. G. Durup, Tightness tests in saltcavern wells, J. Oil \& Gas Sci. and Tech. 56(5) (2002) 451-469.

2. W.G. Liang, C.H. Yang, Y.S. Zhao, et al. Experimental investigation of mechanical properties of bedded salt rock, J. Inter. Jour. of Rock Mecha. and Min. Sci. 44(3) (2007) 400-411.

3. T.T. Wang, H.L. Ma, X.L. Shi, et al. Salt cavern gas storage in an ultra-deep formation in Hubei, China, J. Inter. Jour. of Rock Mecha. and Min. Sci. 102 (2018) 57-70.

4. P.A. Fokker, G.A.M. Kruse, Salt deformation and subsidence, J. Learned and Appli Soil Mecha. 22, (2002) 57.

5. S.L. Furst, S. Doucet, P. Vernant, et al. Monitoring surface deformation of deep salt mining in Vauvert (France), combining InSAR and leveling data for multi-source inversion, J. Solid Earth, 12(1) (2021) $15-34$. 
6. K. Allen, Eminence dome-natural-gas storage in salt comes of age, J. Jour. of Petro. Tech, 24(11) (1972) 1299-1301.

7. K. Allen, Eminence--natural gas storage in salt comes of age, J. Soc. Pet. Eng. AIME (1971), 71.

8. T. Beutel, S. Black, Salt deposits and gas cavern storage in the UK with a case study of salt exploration from Cheshire, J. Oil Gas Europ. Maga. 1 (2005) 3135 .

9. D. J. Evans, S. Holloway, A review of onshore UK salt deposits and their potential for underground gas storage, J. Geo. Society, 313(1) (2009) 39-80.

10. J. G. Gallegos, S. Avila, R. Benyon, et al. Experimental evaluation of the performance of humidity analyzers in natural gas under industrial conditions, J. Jour. of Natural Gas Sci. and Eng. 31 (2016) 293-304.

11. B. Orlic, V. Thienen-Visser, G. J. Schreppers, Numerical estimation of structural integrity of salt cavern wells, 50th US Rock Mechanics/Geomechanics Symposium, OnePetro, 2016.

12. G. Yuan, C. Yang, B. Wang, Y. Drilling and completion technologies for the underground gas storage(UGS) in China: A state-of-the-art appraisal, J. Natural Gas Industry 33(2) (2013) 61-64. 